\title{
Maps of Wales
}

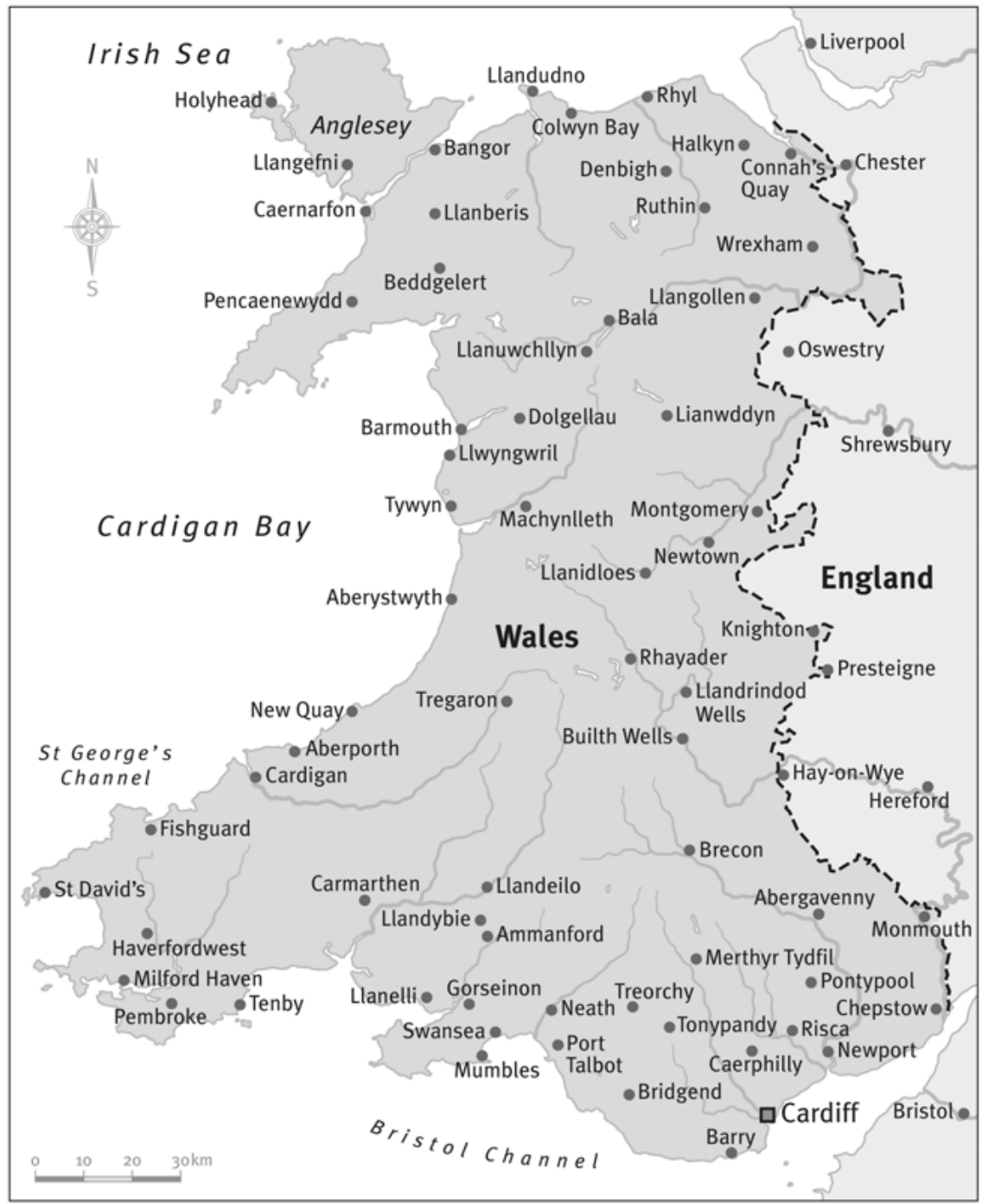

Map 1: Cities, towns and other settlements 


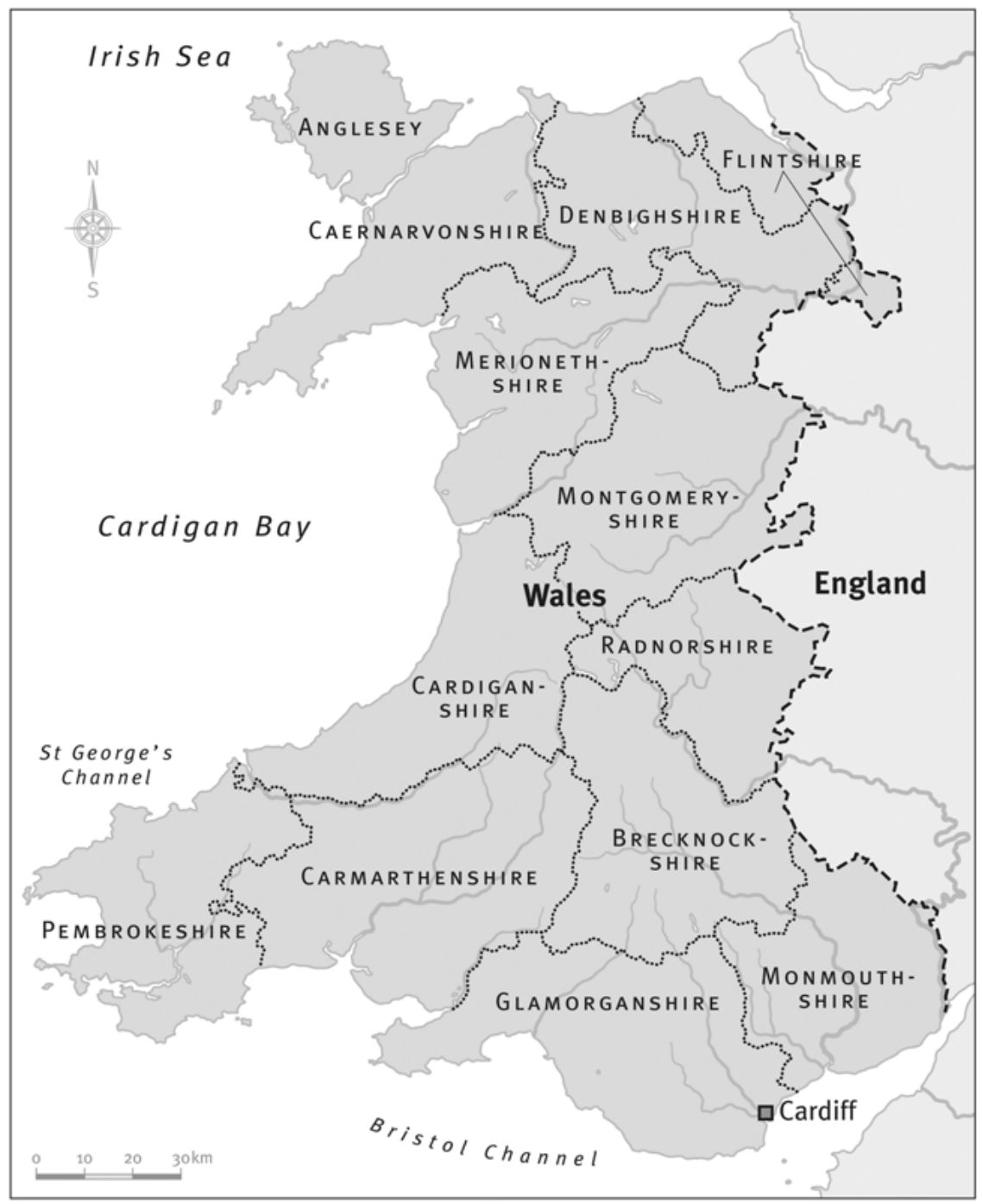

Map 2: The historic or ancient counties of Wales 


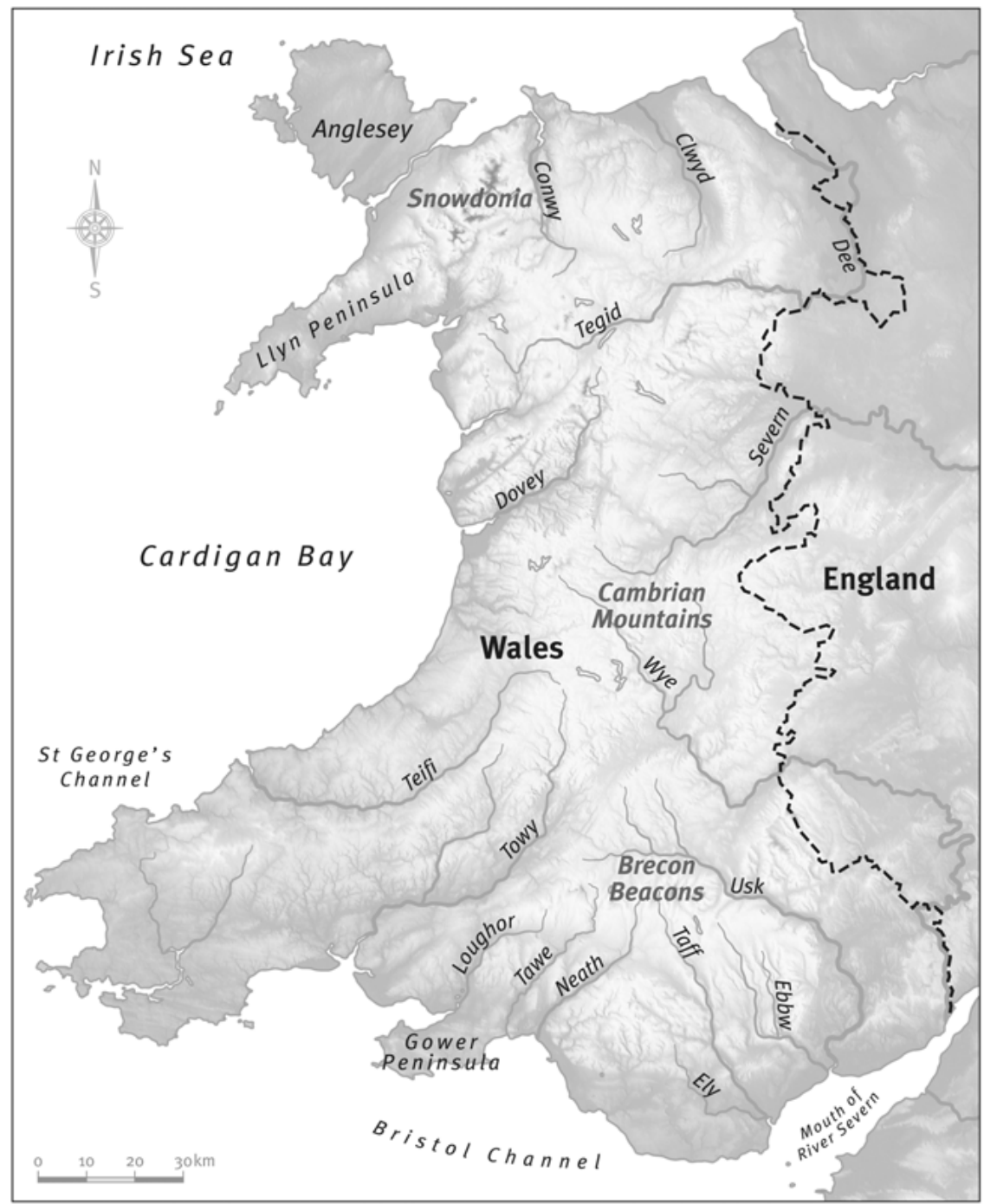

Map 3: Main topographical features of Wales 


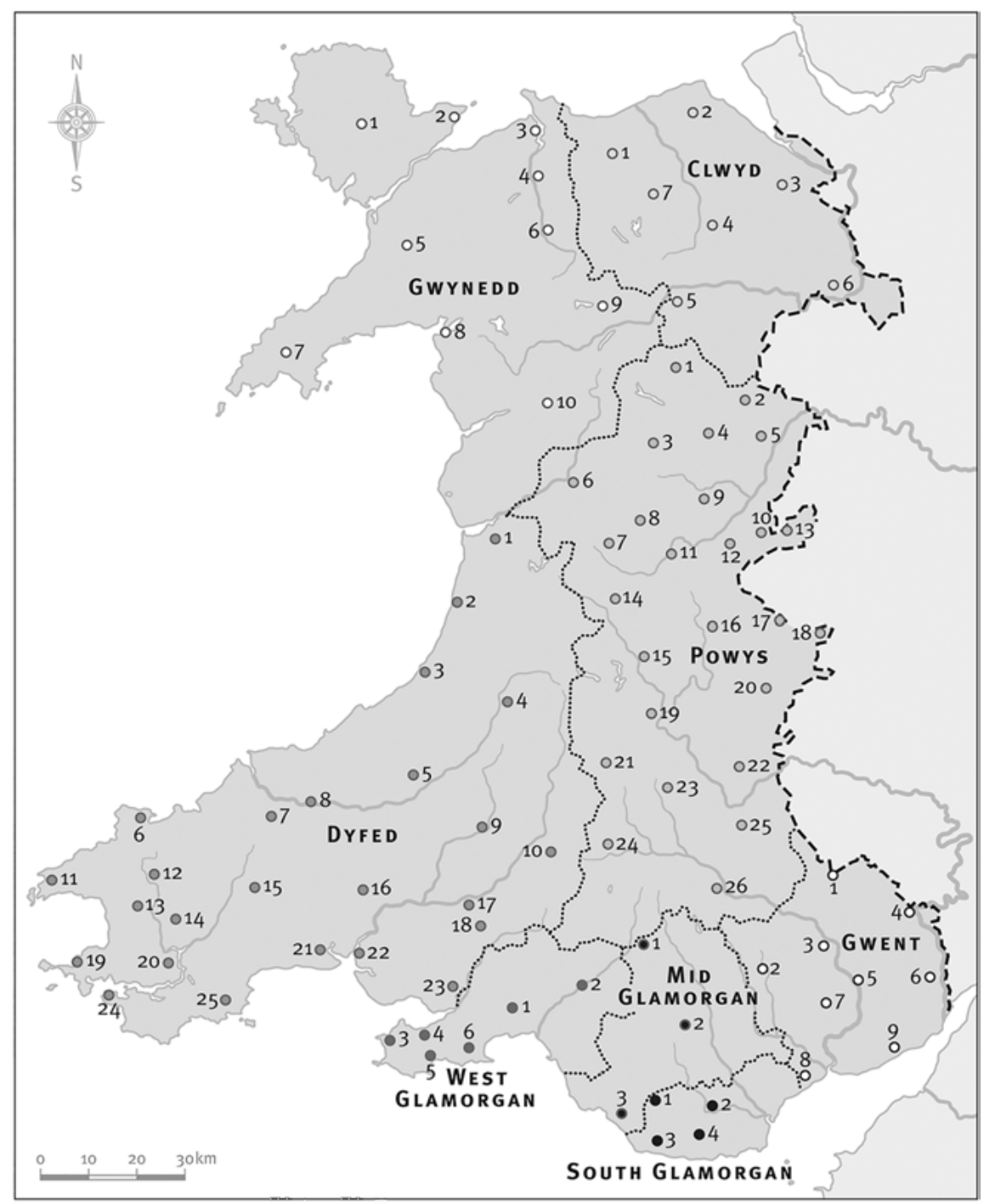

Map 4: Map of the rural locality network of the Survey of Anglo-Welsh Dialects 


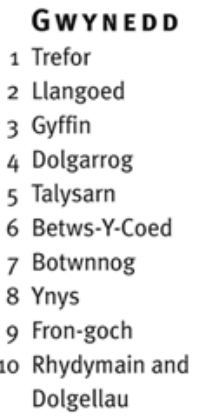

\section{CLWYD}

1 Llanfair Talhaiarn

2 Trelawnyd

3 Buckley

4 Llanfair Dyffryn Clwyd

5 Cynwyd

6 Overton and Bangor-Is-Y-Coed

7 Nantglyn

\section{Powys}

1 Llangynog

2 Llanfechain

3 Foel

4 Pont Robert

5 Guilsfield

6 Cemmaes Road

7 Staylittle

8 Carno

9 Tregynon

10 Forden

11 Llandinam

12 Kerry

13 Churchstoke

14 Llangurig

15 Rhayader
16 Llanbister

17 Knighton and Knucklas

18 Stanage Park

19 Llanafan Fawr

20 New Radnor

21 Llanwrytd Wells

22 Painscastle

23 Upper Chapel

24 Trecastle

25 Talgarth

26 Talybont-on-Usk

\section{DYFED}

1 Furnace

2 Rhydyfelin

3 Llanon

4 Tregaron

5 Lampeter and Drefach

6 Goodwick

7 Boncath

8 Cenarth

9 Llansawel

10 Myddfai

11 St David's

12 Wolf's Castle

13 Camrose

14 Wiston

15 Login

16 Newchurch

17 Gelli Aur

18 Llandybie

19 Marloes

20 Llangwm

21 Laugharne

22 Ferryside

23 Llangennech

24 Angle

25 St Florence

\section{WEST}

GLAMORGAN

1 Glais

2 Resolven

3 Llangennith

4 Llanrhidian

5 Horton

6 Bishopston

\section{MID}

GLAMORGAN

1 Penderyn

2 Porth

3 St Brides Major

\section{SOUTH}

GLAMORGAN

\author{
1 Llangan \\ 2 Peterston-super-Ely \\ 3 Llantwit Major \\ 4 Llancarfan
}

\section{GWENT}

1 Pandy

2 Manmoel

3 Llanofer

4 Rockfield

5 Usk

6 Tintern

7 Llanddewi Fach

8 Marshfield

9 Undy 
